\title{
TEORIA DA ARGUMENTAÇÃO E JURISPRUDÊNCIA DOS VALORES: A FUNDAMENTAÇÃO DAS DECISÕES EM OPOSIÇÃO À IDEIA DE DISCRICIONARIEDADE JUDICIAL
}

\section{ARGUMENTATION THEORY AND JURISPRUDENCE OF VALUE: THE BASIS OF THE DECISION AS OPPOSITION THE IDEA JUDICIAL DISCRETION}

Guilherme César Pinheiro ${ }^{1}$

\begin{abstract}
RESUMO: Considerando que o instituto jurídico processual da decisão jurisdicional ganhou maior relevância no Estado Democrático, este - a partir de uma questão de ordem do STF - Inquérito Policial no 2.424 - objetiva apresentar um ensaio sobre a decisibilidade comparticipada a partir de uma crítica à teoria da ponderação material de valores, principalmente ao seu caráter antidemocrático de aplicação do direito, em face às garantias processuais porque o Supremo Tribunal Federal tem se mostrado adepto da mencionada teoria, usando-a para fundamentar suas decisões. Para tanto, é necessário considerar a distinção entre a fundamentação (discurso de justificação) e a aplicação (discurso de aplicação) das normas, enunciada por Klaus Günther e apropriada por Harbermas. Além disso, é essencial a compreensão do princípio do contraditório como garantia de influência e não surpresa, rechaçando, dessa forma, o conceito do mencionado princípio, apenas como ciência e participação. E assim considerando, serão apresentadas algumas considerações para se estruturar procedimentalidade para uma decisibilidade comparticipada.
\end{abstract}

Palavras Chave: Ponderação de valores; Normas e valores Discurso de aplicação; Princípio do contraditório; Decisão comparticipada.

\begin{abstract}
Considering that the institute legal proceedings of the decision gain more relevance in the Democratic State, this work - from a order's question of the STF - Police Inquiry $n^{\circ}$ 2424-4 - aims to present one essay about a decidability coparticiped from of the one criticism the "Theory of Balacing of Values", mainly, its undemocratic character of law application, concerning constitutional procedural guaranty, because the Supreme Federal Court has seemed to be following this theory., its using for reasons your decisions. For that, it's necessary to consider the distinction between the reasons (justification discourse) and application (application discourse) of the norms, enunciated by Klaus Günther and appropriated for Harbermas. Besides this, it is essential a comprehension The Principle of Contradictory as guaranty of influence and not-surprise, rejecting, this way, the concept of the mentioned principle, only as science and participation. Considering like this, will make some considerations for to structure proceduralism for a decidability coparticiped.
\end{abstract}

Keywords: Balancing values; Rules and values; Application discourse; contradictory principle; Decision co-participaticiped.

\footnotetext{
${ }^{1}$ Graduando em Direito ( $10^{\circ}$ período) pela Faculdade Mineira de Direito da Pontifícia Universidade Católica de Minas Gerias. Estagiário do Ministério Público de Minas Gerais.
} 


\section{INTRODUÇÃO}

Após a instituição do Estado Democrático pela Constituição da República de 1988, o ato decisório passa a ter maior significância, necessitando, então, de uma intensa e contínua pesquisa acerca do assunto com intuito de adequá-lo ao novo paradigma jurídico instituído. Assim, visa-se, neste trabalho, apresentar considerações que possam contribuir para uma estruturação de um espaço-tempo procedimental de construção comparticipada das decisões judiciais, a partir de uma crítica à jurisprudência dos valores.

Nesta perspectiva, há de se distinguirem os discursos de justificação dos discursos de aplicação de normas, caracterizando, principalmente, os últimos. Em seguida, importa visitar a teoria dos princípios jurídicos de Robert Alexy, especialmente no tocante ao modo de aplicação dos princípios e à diferença entre regras e valores. Nessa linha de pensamento, serão analisados os enunciados da teoria de Klaus Günther $(1993$; 1995) sobre os discursos de aplicação e a leitura feita por Habermas (1997) das duas teorias.

Mas não é só. É preciso ainda conjugar os discursos de aplicação com as garantias processuais de índole democrática, sobretudo o princípio do contraditório, esclarecendo sua acepção moderna e destacando sua correlação com a fundamentação das decisões.

Destarte, a decisão jurisdicional não pode ser construída, senão de maneira comparticipada e policêntrica, ao contrário do proposto pela sofisticada teoria dos princípios de Robert Alexy, que confunde o que é devido (obrigatório ou permitido - o Direito) com aquilo é negociável ou passível de preferências (valores), prescrevendo, também, um modo arbitrário de aplicação de princípios (lei da ponderação).

No entanto, o Supremo Tribunal Federal mostrou não ter compreendido os preceitos e limites impostos pelo novo paradigma no tocante ao instituto estudado, uma vez que em resposta a uma questão posta pelo presidente do STJ (Inquérito Policial $n^{\circ} 2.424-4$ ) que servirá de base para o presente, mostrou-se adepto à teoria alexiana. Todavia, não é o mais grave, uma vez que a questão de ordem foi respondida (decidida) sem a devida participação dos envolvidos, em flagrante ofensa à garantia constitucional do contraditório e, por conseguinte, a fundamentação das decisões, tendo em vista a correlação entre as duas. 


\section{RECONSTRUÇÃO DO FATO (INQUÉRITO POLICIAL Nº . 2.424-4)}

O caso concreto usado para a elaboração do presente trabalho trata-se de uma questão de ordem em que o presidente do STJ pede ao STF autorização para usar provas produzidas por meio de interceptação telefônica e escuta ambiental, com autorização judicial, a fim de instaurar e instruir procedimento administrativo disciplinar contra servidores, por conta de ilícitos ligados aos mesmos fatos apurados no inquérito, pois a Constituição da República (artigo 5, XII) e a Lei $n^{\circ}$. 9.296/96 permitem a quebra de sigilo das comunicações telefônicas somente para fins de investigação criminal ou instrução processual penal.

Objetivando responder a questão posta pelo requerimento do presidente do STJ, o relator buscou a resposta na doutrina. Contudo, não havia um entendimento pacificado, seja na jurisprudência do Tribunal seja no debate doutrinário. Ademais, a questão posta pelo presidente do STJ foi decidida de forma abstrata, haja vista que a decisão do STF desconsiderou a participação das partes afetadas pela decisão jurisdicional, que implicará na utilização de provas no procedimento administrativo disciplinar, o que configura, conforme já dito, uma flagrante ofensa ao princípio do contraditório e, por conseguinte, à fundamentação da decisão.

Em seguida, o Ministro-relator, a partir de uma interpretação axiológica das disposições constitucionais atinentes ao tema - exceção à inviolabilidade das comunicações telefônicas (artigo $5^{\circ}$, XII da CR/88) e, por conseguinte, da inadmissibilidade de provas ilícitas (artigo $5^{\circ}$, LVI da CR/88) -, procede ao balanceamento (ponderação) entre a garantia da intimidade (relacionada, neste caso, com a produção de prova) e a própria prova já produzida, o que pressupõe ser a Constituição uma ordem concreta de valores, confundindo, portanto, o Direito (aquilo que é devido) com Valores (aquilo que é cambiável, negociável). Concluiu, por fim, que há um interesse público de instauração e instrução de procedimento com intuito de punir aqueles que praticam ilícitos graves superior ao interesse privado da intimidade. Portanto, este há de sucumbir àquele, nos seguintes termos:

Não há duvida de que, no primeiro aspecto, o da produção, a restrição constitucional
tem por objetivo claro preservar a intimidade, como bem jurídico privado, mas essen-
cial a dignidade da pessoa humana, até o limite em que tal valor, aparecendo como
obstáculo ou estorvo concreto à repressão criminal, tem de ceder a manifesta superio-
ridade do interesse público na apuração e punição de crime grave, enquanto o mais
conspícuo dos atentados às condições fundamentais de subsistência da vida social. O
limite da garantia da intimidade é aí, nessa primeira regra, de cunho restritivo, obje-
to da ponderação de valores formulada pela constituição mesma, que não podendo
condescender com a impunidade de fato erosivo das bases estruturais da convivência 
social, sacrifica aquela para garantir esta, dando primazia a um valor sobre o outro. Nesse sentido, costuma dizer-se que a garantia não serve a proteger atividades ilícitas ou criminais. "Daí, autorizar, em caráter excepcional, seja interceptada comunicação telefônica, apenas quando tal devassa e revele como fonte de prova imprescindível à promoção do fim público da persecução penal. (BRASIL, 2007, p. 6). Grifos nossos e do original).

Nestes termos, o plenário do STF acordou no sentido de autorizar a utilização da prova produzida mediante interceptação telefônica e escuta ambiental para fins de instruir e instaurar procedimento administrativo contra os servidores, por conta de ilícitos ligados aos fatos apurados no inquérito, no qual foi autorizada a quebra da inviolabilidade da intimidade, sob o argumento de que o direito fundamental à intimidade (bem jurídico privado) deve ser limitado, excepcionalmente neste caso, em razão da manifesta superioridade do interesse público na apuração de crime grave, afirmando-se, inclusive, que o mencionado direito fundamental não serve a proteger atividades ilícitas. Ou seja, entendeu-se que o direito fundamental à intimidade e sua relação com a produção de provas devem ceder diante do interesse público superior na apuração e punição de crime grave.

O objeto (mérito) da decisão ora analisada diz respeito à prova emprestada, fato que exige, para uma melhor compreensão do assunto, que se faça uma breve exposição a respeito do tema, abordando o conceito e os requisitos da prova emprestada, além de perquirir acerca da possibilidade ou não do aproveitamento da prova obtida por meio de interceptação telefônica e escuta ambiental em procedimento de natureza não penal.

\section{PERSPECTIVA DA DOGMÁTICA SOBRE O TEMA}

Passa-se, então, à abordagem doutrinária atinente ao instituto da prova emprestada.

Prova emprestada é aquela produzida num processo, sendo depois transportada documentalmente para outro, visando gerar efeitos neste. (GRINOVER; FERNANDES; GOMES FILHO, 2006, p. 125). É o aproveitamento de atividade probatória anteriormente desenvolvida, mediante translado dos elementos que a documentam (TALAMINI, 1998, p. 146). Todavia, esse aproveitamento, através do transporte documental da prova, não se realiza sem que se cumpram alguns requisitos. Quais são esses requisitos?

Eduardo Talamini (1998) é o autor que confere maior destaque a esse assunto. Segundo o autor, em respeito aos princípios do contraditório e do juízo natural, são essenciais para 
a admissibilidade desse tipo de prova a "presença das partes" (contraditório) e a "presença do juiz", juízo natural/jurisdição, (TALAMINI, 1998). Ou seja, as partes do processo em que a prova será transposta para outro processo devem participar nesse ato em contraditório sobre a direção do mesmo juízo daquele processo.

Esse mesmo autor lembra ainda outros requisitos que ele próprio denomina de "legais”. Tais requisitos trazem a ordem de observar as prescrições atinentes à natureza originária da prova tanto no primeiro processo quanto no segundo. Neste devem ser respeitadas as regras atinentes à prova documental, visto que é sob essa forma que se dá o translado (TALAMINI, 1998).

O professor José Carlos Barbosa Moreira também destaca a participação dos envolvidos, ou melhor, contra quem se pretende opor tal prova, dizendo: “[...] à prova "emprestada", isto é, transferida de um para outro processo, contanto que a pessoa a quem se pretende opor a prova haja participado do feito em que ela se produzira" (BARBOSA MOREIRA, 1995, p. 133).

Não há dúvida de que o ato de translado de prova(s) de um procedimento para o outro, como qualquer ato de produção de provas, há de passar pelo crivo do contraditório. Não obstante o exposto, no vertente caso, não foi respeitado o requisito da prova emprestada atinente ao contraditório, porque o translado da prova de um processo para outro foi deferido sem a participação da parte a quem se opõe a prova, o que implica prejuízo aquela. Portanto, deve-se reconhecer a nulidade do ato.

De resto, cabe perquirir acerca da possibilidade ou não de se utilizarem provas produzidas por meio de interceptação telefônica e escuta ambiental.

Greco Filho (1996) responde de forma negativa, já que tanto a CF/88 quanto a Lei $n^{\circ}$ 9.296/96 teriam limitado, de modo absoluto, a violação ao sigilo das comunicações telefônicas nas hipóteses de investigação criminal e instrução processuais penal, ficando, assim, vedado o aproveitamento da prova produzia sob essas condições em outro processo (TALAMINI, 1998; GOMES; CERVINI SANCHEZ, 1997; BARBOSA MOREIRA, 1995). Vejamos:

Poderia a prova obtida com interceptação legalmente realizada para fins de investigação criminal servir em processo civil como prova emprestada?’[...]

[...] Cremos que não, por que, no caso, os parâmetros constitucionais são limitativos. A finalidade de interceptação, investigação criminal e instrução processual penal é, também, a finalidade da prova, e somente nessa sede pode ser utilizada. [...] (GRECO FILHO, 1996, p. 50-51). 
Por outro lado, há autores, como por exemplo, Grinover, Fernandes e Gomes Filho, (2006) que protestam pela admissibilidade do empréstimo de prova produzida mediante quebra de sigilo das comunicações telefônicas, desde que legítima, ou seja, observadas as prescrições da $\mathrm{CF} / 88$, bem como da Lei $\mathrm{n}^{\circ}$ 9.296/96, tendo que uma vez rompida a intimidade, na forma da lei e da Constituição, nada mais resta a resguardar.

No entanto, na perspectiva de Estado Democrático de Direito, não existe superioridade de um interesse (esfera ou autonomia) público - como o da produção de provas para fins de instrução e apuração de crime - em relação a um interesse (esfera ou autonomia) privado - como o da intimidade, e vice-versa, porque esse paradigma estrutura-se a partir de ideia de co-originalidade entre as autonomias privada e pública. Isto é, as autonomias pública e privada se pressupõem mutuamente (HABERMAS, 2000, p. 153). Não existe sequer "choque ou conflito" entre estas duas esferas, pois ambas devem conviver harmonicamente dentro do mesmo ordenamento jurídico, sem, contudo, que o caráter normativo/deontológico do Direito seja prejudicado. Dessa forma, a fundamentação do julgado do Inquérito Policial n ${ }^{\circ}$. 2.424-4 deveria ter tratado mais objetivamente de seu mérito (a possibilidade ou não de utilização de provas produzidas mediante interceptação telefônica em procedimentos não criminais), de acordo com o caso concreto; ao invés de trata acerca do conflito entre os interesses (valores) da produção de provas para fins de instrução e apuração de crime e o da intimidade. Assim sendo, conclui-se que, se a Constituição garante a inviolabilidade do sigilo da correspondência e das comunicações telegráficas, de dados e das comunicações telefônicas; permitindo, no entanto, no último caso, que por ordem judicial, nas hipóteses e na forma estabelecidas pela Lei $n^{\circ} .9 .296$, rompa-se à intimidade, para fins de investigação criminal ou instrução processual penal, é tão-somente nesta hipótese que se pode violar a garantia da intimidade com intuito de produção de provas.

Portanto, não se permite ao legislador ordinário muito menos ao Judiciário à relativização (flexibilização) de qualquer direito fundamental, principalmente se pautada numa argumentação axiológica.

O importante, neste trabalho, é analisar que os argumentos que justificam, ou tentam justificar a decisão amoldam-se com a chamada jurisprudência dos valores, assim entendida como uma linha teórica argumentativa desenvolvida a partir da distinção entre regras e princípios, estes entendidos como mandamentos de otimização, isto é, ordem de realizar algo da melhor maneira possível entre as existentes, prescindido também da diferenciação entre os discursos de justificação e aplicação das normas, uma vez que, nesse marco, os argumentos de espectro axiológico, moral, pragmático e ético são válidos tanto nos discursos de justificação 
- que objetiva a positivação de normas, e referem-se à validade destas - quanto nos discursos de aplicação - destinados à dedução lógica de qual a norma, dentre as prima facie aplicáveis, é adequada ao caso.

\section{DISCURSOS DE APLICAÇÃO DAS NORMAS E PONDERAÇÃO MATERIAL DE VALORES: UMA ABORDAGEM À LUZ DA TEORIA PROCEDIMENTALISTA DO DIREITO}

Percebe-se, pelo exposto acima, que a jurisprudência dos valores, pressupondo ser a constituição uma ordem concreta de valores, faz uma confusão entre Direito (aquilo que é devido, obrigatório ou permitido) e valores (aquilo que é negociável e passível de preferências), negando, então, o caráter obrigatório do Direito. Além do mais, prescinde da limitação de espectro argumentativo imposta pela distinção entre os discursos de aplicação e justificação. Destaca-se a respeito do assunto a denúncia feita por Cattoni de Oliveira, quando também critica um acórdão do STF - HC n. 82424-2 RS/caso Ellwanger:

\footnotetext{
Esse entendimento judicial, que pressupõe a possibilidade gradual, numa maior ou menor medida, de normas, ao confundi-las com valores, nega exatamente o caráter obrigatório do Direito. Tratar a Constituição como uma ordem concreta de valores é definir o que pode ser discutido e expresso como digno de valores, pois só haveria democracia, nesse ponto de vista, sob o pressuposto de que todos os membros de uma sociedade política compartilham, ou tenham de compartilhar, de modo comunitarista, os mesmos supostos axiológicos, uma mesma concepção de vida e de mundo. (CATTONI DE OLIVEIRA, 2007, p. 119)
}

Feita essas considerações introdutórias acerca do problema posto, passa-se a discorrer sobre a aplicação do Direito em dois dos mais importantes juristas contemporâneos que trabalham no âmbito da teoria da argumentação: Klaus Günther e Robert Alexy, a partir da diferença, proposta pelo primeiro, entre discurso de justificação e aplicação; interligando os ensinamentos de Günther com os estudos de Alexy acerca dos princípios jurídicos; sem se esquecer da rica contribuição de Jürgen Harbemas.

Segundo Klaus Günther, os discursos de justificação referem-se à validade de normas, ou seja, trata-se de uma interação argumentativa objetivando a positivação de normas, pressupondo a consideração dos interesses de todos. Nestes, o âmbito argumentativo é mais amplo do que os discursos de aplicação, uma vez que os participantes pode valer-se de razões éticas, 
morais, axiológicas e pragmáticas, no espaço-tempo procedimental institucionalizado pelo devido processo legislativo:

A positivação de normas jurídicas deve ser institucionalizada em procedimentos que correspondem às regras de discursos práticos, de modo que os interesses individuais possam ser respeitados²(GÜNTHER, c1993, p. 270-271).

Discurso de aplicação, por sua vez, diz respeito à adequabilidade de uma norma, dentre as aplicáveis prima facie, ao caso concreto. Tratando-se de discurso de aplicação a esfera argumentativa limita-se a razões de cunho técnico-jurídico, sendo imprescindível a descrição completa do caso, bem como a consideração de todas as variantes semânticas das normas prima facie aplicáveis:

En el discurso de aplicación cambia el ponto de vista desde el que se tematiza una norma. En vez de enjuiciar su validez, ahora se aprecia su referencia a la situación. Puede determinarse qué norma es adecuada en una situación si los participantes se han referido a todas las normas aplicables prima facie a una descripción completa" (GÜNTHER, c1995, p. 287).

Os discursos-jurídicos de aplicação têm como objetivo a dedução-lógica-racional de qual norma, dentre as primas facie aplicáveis, é adequada ao caso concreto. Aqui, pressupõe-se, a partir de uma exaustiva reconstrução fática do caso, uma permanente problematização, com vistas à estruturação da comparticipação e do policentrismo da construção e fiscalização das decisões judiciais. Vejamos as lições de Habermas:

[...] encontrar entre as normas aplicáveis prima facie aquela que se adapta melhor à situação de aplicação descrita de modo possivelmente exaustivo e sob todos os pontos de vista relevantes. É preciso estabelecer um nexo racional entre a norma pertinente e as normas que passam para o pano de fundo, de tal modo que a coerência do sistema de regras permaneça intocada em seu todo. As normas pertinentes e as retroativas não relacionam entre si como valores concorrentes, os quais, na qualidade de mandamentos de otimização, seriam realizados em diferentes níveis: porém, como normas "adequadas" ou "não-adequadas". Ora, adequação significa a validade de um juízo deduzido de uma norma válida, através do qual a norma subjacente é satisfeita (HA-

BERMAS, 1997, p. 322-323).

Por fim, Habermas alerta para um ponto importantíssimo: a consideração (participação) dos interesses dos envolvidos no discurso de aplicação, nos seguintes termos:

\footnotetext{
${ }^{2}$ No original "The positing of legal norms must be institutionalized in procedures which correspond to the rules of prarictical discourse, so that the interests of each individual con receive their due regard".
} 
Questões de aplicações de normas afetam a autocompreensão e a compreensão do mundo dos participantes, porém não do mesmo que os discursos de fundamentação. Nos discursos de aplicação, as normas, supostas como válidas, referem-se sempre aos interesses de todos os possíveis atingidos; no entanto, quando se trata de saber qual norma é adequada a um acaso determinado, essas relações se retraem atrás dos interesses das partes imediatamente envolvidas (HABERMAS, 1997, p. 284).

Em sentido oposto à teoria acima enunciada, Robert Alexy afirma que o discurso jurídico é um caso especial do discurso prático geral, diferenciado estes dos primeiros apenas pelo fato de aqueles serem institucionalizados por normas. Logo, seria permitido que os participantes dos discursos de aplicação valessem de argumentos morais (ALEXY, 1999, p. 27).

Nessa linha de pensamento, percebe-se uma estreita relação de seu conceito e diferenciação dos discursos de aplicação com sua teoria dos princípios, na qual, os distingue das regras, e, principalmente, de sua metodologia de aplicação.

Nesse diapasão, é preciso visitar a teoria dos princípios jurídicos de Alexy. Este criticando a distinção proposta por alguns autores, por exemplo, Noberto Bobbio ${ }^{3}$ apresenta uma distinção, que ele próprio chama de qualitativa, entre regras e princípios, sendo que ambos são espécies do gênero norma, entendida como "o significado de um enunciado normativo" (ALEXY, 2008, p. 58). A partir disso, caracteriza os princípios como mandamentos de otimização, isto é, ordem de se realizar algo na melhor medida possível entre as existentes, enquanto regras são determinações que devem ser cumprida, obedecidas ou não. Veja-se:

\footnotetext{
Princípios são, por conseguintes, mandamentos de otimização, que são caracterizados por poderem ser satisfeitos em graus variados e pelo fato de que a medida devida de sua satisfação não depende somente das possibilidades fáticas, mas também das possibilidades jurídicas. O âmbito das possibilidades jurídicas é determinado pelos princípios e regras colidentes. Já as regras são normas que são sempre satisfeitas ou não satisfeitas. Se uma regra vale, então, deve se fazer exatamente aquilo que ela exige; nem mais, nem menos. Regras contêm, portanto, determinações no âmbito daquilo que é fática e juridicamente possível. Isso significa que a distinção entre e princípios é uma distinção qualitativa, e não uma distinção de grau. Toda norma é ou uma regra ou um princípio (ALEXY, 2008, p. 90-91).
}

Além disso, diferencia o modo de aplicação das duas espécies de normas. Regras seriam aplicadas de maneira silogística e, havendo conflito entre elas, uma seria válida e a outra não. Já os princípios se aplicam por meio de balanceamento e, ao contrário das regras, um

${ }^{3}$ Noberto Bobbio é um dos autores que distingue regras e princípios pelo critério da generalidade. Segundo Alexy, a generalidade seria uma consequência do princípio, mas não a causa. Galuppo (1998) e, ainda, Pedron (2005). 
principio não exclui o outro, no caso de colisão, nos termos da lei da ponderação, que dispõe: "Quanto maior for o grau de não-satisfação ou de afetação de um princípio, tanto maior terá que ser a importância da satisfação do outro" (ALEXY, 2008, p. 167). No mais, esclarece que esta lei estabeleceria um balanceamento (peso, prevalência ou preferência) relativo, nunca absoluto.

O principal e basilar equívoco dessa teoria reside em equiparar os princípios jurídicos, enquanto espécie do gênero norma, a valores. As normas diferem dos valores por quatro motivos: o primeiro, porque norma traduz a ideia de uma ação obrigatória, enquanto valor refere-se às ações teleológicas; o segundo, atinente à validade, porque normas são válidas ou inválidas sem exceções - código binário -, o que não ocorre com os valores, visto que um apenas se sobrepõe ao outro, não o invalidando; o terceiro, diz respeito à obrigatoriedade absoluta das normas e relativas dos valores; o quarto e último refere-se ao conflito entre normas ou entre valores; porquanto, normas conflituosas não podem coexistir no mesmo ordenamento jurídico, pois integram um sistema coerente, ao passo que valores contraditórios visam obter superioridade em relação aos outros. Importa transcrever essa esclarecedora distinção nas palavras de Habermas:

Princípios ou normas mais elevadas, em cuja luz outras normas podem ser justificadas, possuem sentido deontológico, ao passo que os valores têm um sentido teleológico. Normas válidas obrigam seus destinatários sem exceção e em igual medida, a um comportamento que preenche expectativas generalizadas, ao passo que valores devem ser entendidos como preferências compartilhadas intersubjetivamente. Valores expressam preferências tidas como dignas de serem desejadas em determinadas coletividades, podendo ser adquiridas ou realizadas de um agir direcionado a um fim. Normas surgem com pretensão de válida binária, podendo ser válidas ou inválidas; em relações a proposições normativas, como nos casos de proposições assertóricas, nós só podemos tomar decisões dizendo "sim" ou "não", ou abster-nos do juízo. Os valores, ao contrário, determinam relações de preferências, as quais significam que determinados bens são mais atrativos que outros; por isso, nosso assentimento a proposições pode ser maior ou menor. A validade deontológica de normas tem sentido absoluto de uma obrigação incondicional e universal: o que deve ser pretende ser igualmente bom para todos. Ao passo que a atratividade de valores tem o sentido relativo de uma apreciação de bens, adotada ou exercida no âmbito de formas de vida ou de uma cultura: decisões valorativas mais graves ou preferências de ordem superior exprimem aquilo que, visto no todo, é bom para nós (ou para mim). Normas diferentes não podem contradizer umas às outras, caso pretendam validade no mesmo círculo de destinatários; devem estar inseridas num contexto coerente, isto é, formar um sistema. Enquanto valores distintos concorrem para obter primazia; na medida em que encontram reconhecimento intersubjetivo no âmbito de uma cultura ou forma de vida, eles formam configurações flexíveis e repletas de tensões (HABERMAS, 1997, p. 316-317). 
Ora, observando a argumentação desenvolvida pelo ministro-relator do julgado do STF (Inquérito Policial no . 2.424-4), sobretudo ao trecho acima transcrito, conclui-se que esta se alinha à teoria alexiana, visto que concebe a Constituição como uma ordem de valores, mencionando várias vezes que a garantia constitucional da intimidade fora objeto de ponderação de valores pelo legislador; afirma, ainda, haver uma primazia relativa de um direito fundamental sobre o outro; além do mais, os argumentos da decisão não respeitam a distinção entre os discursos-jurídicos de aplicação e justificação; porquanto, o relator se refere às questões de validade da norma (discurso de justificação), quando deveria perquirir acerca da adequação das normas prima facie aplicáveis ao vertente caso.

Ressalta-se a importância da distinção entre os discursos-jurídicos de aplicação e justificação, uma vez que não há que se discutir a realização de valores nos processos jurisdicionais, eis que, caso tal fato seja admitido, a jurisdição extrapolaria seu âmbito de incidência, tornando-se, portanto, autoritária, ferindo, inclusive, o art. $2^{\circ}$ da Constituição, haja vista que, grosso modo, sua função é aplicar o direito vigente ao caso concreto levado a juízo. Nesse norte, destaca-se o pensamento de Habermas (1997, p321):

Ao deixar-se conduzir pela idéia da realização de valores matérias, dados preliminarmente no direito constitucional, o tribunal constitucional transforma-se numa instância autoritária. No caso de uma colisão, todas as razões podem assumir o caráter de argumentos de colocação de objetivos, o que faz ruir a viga mestra introduzida no discurso jurídico pela compreensão deontológica de normas e princípios do direto.

No mesmo sentido, comenta Cattoni de Oliveira (2007, p.120-121):

[...] jurisprudência dos valores, não corresponde a uma garantia consistente dos direitos, já que, por um lado, submete o exercício desses direitos a um cálculo de custo/benefício, e, por outro, faz do tribunal um poder legislativo de segundo grau, a controlar, de uma perspectiva legislativa e não jurisdicional, as escolhas políticas legislativas e executivas, assim como as concepções de vida digna dos cidadãos, à luz do que seus 11 Ministros consideram ser o melhor - e não o constitucionalmente adequado - para a sociedade brasileira.

Além do que, a lei de ponderação, elaborada por Alexy, não prescreve uma relação de prevalência absoluta de um princípio sobre outro, nem tampouco determina critérios racionais para isso. Logo, a ponderação material de valores se operará de forma autoritária, uma vez que o balanceamento fica a cargo do juízo singular ou do órgão colegiado (o tribunal), o que retira 
o caráter comparticipativo e policentrico não só da construção do ato decisório, mas também da atividade jurisdicional, o que resulta na confusão entre esta e a atividade judicacional dos instrumentalistas, aqui entendida como uma atuação solipsista (discricionária) do juiz, em preterição das garantias processuais, com vistas a atingir os escopos metajurídicos do processo.

Tanto é assim, que o próprio Alexy confessa no posfácio da tradução para o português de sua grande obra sobre o tema, publicada em 2008, haver discricionariedade judicial na ponderação material de valores. Vejamos:

Os direitos fundamentais não são um objeto passível de ser dividido de uma forma refinada que inclua impasses estruturais - ou seja - impasses reais no sopesamento -, de forma a torná-los praticamente sem importância. Neste caso, então, existe uma discricionariedade para o sopesar, uma discricionariedade tanto do legislativo quanto do judiciário (ALEXY, 2008, p. 611).

Entretanto, nas democracias, em decorrência das conquistas histórico-teóricas da humanidade - Direitos e Garantias Fundamentais - a Jurisdição atua e se legitima pelo devido processo legal, que busca afastar qualquer subjetivismo e discricionariedade na atuação daquela. Esta é a denúncia feita por Rosemiro Pereira Leal (2009, p.28) :

[...] atualmente, com as conquistas histórico-teóricas de direitos fundamentais incorporadas ao processo, como instrumentalizador e legitimador da Jurisdição, a atividade jurisdicional não é mais um comportamento pessoal do juiz, mas uma estrutura procedimentalizadora de atos jurídicos seqüenciais a que se obriga o órgão judicial pelo controle que lhe impõe a norma processual legitimando-o ao processo. Portanto, não há para o órgão judicial qualquer folga de conduta subjetiva ou flexibilização de vontade, pelo arbítrio ou discricionariedade, no exercício da função jurisdicional, porque, a existirem tais hipóteses, se quebraria a garantia de simétrica paridade do processo (grifo do original).

Destarte, no paradigma do Estado Democrático de Direito a aplicação do direito não pode se realizar, senão a partir da distinção de discurso de justificação do discurso de aplicação, sendo que essa última se dá mediante uma descrição completa do caso concreto, buscando deduzir qual norma é adequada ao caso, dentre as prima facie aplicáveis, e, principalmente, com uma efetiva participação dos envolvidos, visto que a melhor maneira de atingir a adequabilidade, sem sombra de dúvida, é discursivamente.

O processo jurisdicional é o instrumento para se atingir a discursividade. Mas há ressalvas a serem feitas, pois é preciso esclarecer qual a compreensão que se tem de processo e 
de sua principiologia. A final, proposta é no sentido de buscar discursivamente um senso de adequabilidade.

\section{O CONTRADITÓRIO COMO GARANTIA DE INFLUÊNCIA E NÃO-SURPRESA: UMA CORRELAÇÃO COM A FUNDAMENTAÇÃO DAS DECISÕES JUDICIAIS}

Quem assegura essa discursividade é o devido processo legal, cuja viga-mestra é o princípio do contraditório. Contudo, tal garantia precisa ser compreendida à luz do Estado Democrático de Direito. Para tanto, é essencial considerar a revisitação ao princípio em questão e a distinção entre processo e procedimento, feitas por Elio Fazzalari; além do estudo que Aroldo Plínio Gonçalves fez sobre as lições deste autor italiano. Daí notará que o princípio do contraditório é correlato a outros princípios constitucionais do processo, especialmente ao da fundamentação das decisões, o que exige considerar o processo como uma garantia constitutiva de direitos fundamentais, numa relação de codependência (BARROS, 2008).

Para o mencionado processualista italiano o contraditório é o elemento que caracteriza o processo, tendo em vista a distinção lógico-inclusiva entre este e o procedimento. Nessa perspectiva, procedimento é uma estrutura técnica-normativa composta por uma sequência de atos jurídicos conexos entre si preparatória do provimento (GONÇALVES, 1992, p. 115).

Processo, por sua vez, é espécie do gênero procedimento, realizado em contraditório em simétrica paridade pelos envolvidos no sentido de influenciar o julgador na construção do ato decisório. Nas palavras de Fazzalari (2006, p. 120):

\footnotetext{
Existe, em resumo, o "processo", então, quando, em uma ou mais fases do iter de formação de um ato é contemplada a participação não só - e obviamente - do seu autor, mas também dos destinatários dos seus efeitos, em contraditório, de modo que eles possam desenvolver atividades que o autor do provimento deve determinar, e cujos resultados ele pode desatender, mas não ignorar.
}

A partir disso, o princípio do contraditório não mais pode ser visto como querem os instrumentalistas, apenas como bilateralidade de audiência assentado no binômio ciência e participação oriundo da expressão latina "audita altera pars", nem como o dizer e o contradizer acerca dos pontos controvertidos da demanda, o que pode ser denominado de "pseudo-contraditório”. Assim são as lições do Prof. Aroldo Plínio Gonçalves (1992, p. 127): 
O contraditório não é o "dizer" e o "contradizer" sobre matéria controvertida, não é a discussão que se trava no processo sobre a relação de direto material, não é a polêmica que desenvolve em torno dos interesses divergentes sobre o conteúdo do ato final. Essa é a sua matéria, o seu conteúdo possível.

Em direito processual democrático, o contraditório é a garantia de oportunidade dos envolvidos (aqueles que sofrerão os efeitos do provimento final ou interlocutório) de participarem de forma influente e discursiva na construção do provimento.

A acepção do contraditório como garantia de influência mostra-se intimamente relacionada com a imposição (garantia) de fundamentação das decisões pelo julgador, vez que a efetividade do contraditório será alcançada tão-somente se o magistrado considerar os argumentos trazidos pelos envolvidos para o espaço-tempo procedimental discursivo. Logo, a fundamentação das decisões deve, essencialmente, percorrer o conteúdo do contraditório.

Dessa forma, vislumbra-se ainda a garantia de não surpresa; porquanto, considerando a correlação com a fundamentação das decisões, é vedado ao juiz motivar suas decisões com argumentos não suscitados pelas partes, o que impõe ao magistrado o dever de provocar o debate acerca de todas as questões, inclusive as matérias de conhecimento oficioso, conforme preceitos da legislação estrangeira - art. 16 do Novo Código de Processo Civil da França; § 139 da ZPO alemã; art. 3, item 3, do Código de Processo Civil de Portugal. Posto isso, o contraditório vem sendo concebido como garantia de influência e não-surpresa (NUNES, 2008, p. 224-239).

Tal compreensão transfere a decisibilidade da órbita do monocentrismo para o policentrismo. Acerca disso, Flaviane de Magalhães Barros (2008, p.18-19) faz a seguinte paródia:

[...] o contraditório não permite que o juiz, no processo jurisdicional, retire um coelho da cartola, como se fosse um mágico. Ou seja, a decisão não é produto somente do juiz, mas esforço argumentativo das partes, pois o contraditório é princípio da influência e da não-surpresa.

Essas ideias da garantia do contraditório como influência e não-surpresa, assim como a sua correlação com a fundamentação das decisões objetivam a estruturação de uma procedimentalidade de construção comparticipada do provimento, afastando, por conseguinte, qualquer subjetivismo da atividade jurisdicional. Isto possibilitará que o ato decisório seja resultado lógico-argumentativo das alegações das partes afetadas por aquele. Ao contrário do acórdão do Inquérito Policial n ${ }^{\circ}$. 2.424 do STF, que se funda em argumentos não suscitados pelas partes, a partir de uma argumentação axiológica, sendo, portanto, fruto de um juízo solipsista do órgão colegiado prolator do acórdão. 


\section{CONCLUSÃO}

A proposta de um ensaio para uma decisibilidade comparticipada atrela-se à noção de processo como garantia constitutiva de direitos fundamentais, numa relação de codependência. A partir dessa acepção, é possível preconizar que a aplicação do direito se dê de modo a garantir a ampla participação dos envolvidos na construção dialética do ato decisório. Pressupõe-se, para tanto, uma estrutura procedimental de problematização de todas as alegações e argumentos jurídicos relevantes para o caso concreto.

Nessa linha de pensamento, a ponderação material de valores se coaduna com os preceitos do Estado Democrático de Direito, porque confunde o Direito com valores e, principalmente, por privilegiar o arbítrio na aplicação do direito, fato que confunde a atividade jurisdicional com a atividade judicacional, esta entendida como aquela que busca atingir os escopos metajurídicos do processo, para suprir os pontos falhos do ordenamento jurídico, por meio de uma atuação discricionária do juiz, em preterição das garantias processuais. Com efeito, o caráter dialético da construção do ato decisório resta prejudicado, porque a garantias processuais dos cidadãos são suprimidas, especialmente o princípio do contraditório e a fundamentação das decisões judiciais. Um bom exemplo de um caso concreto é o julgado em análise, o qual se funda em argumentos axiológicos e prescinde das alegações suscitadas pelas partes envolvidas, o que retira a comparticipação na construção do provimento, sendo, portanto, fruto de juízo solipsista, reitera-se.

Assim sendo, o princípio do contraditório, na acepção de influência e não surpresa, passa a ser o eixo central do processo constitucional, para se estruturar uma procedimentalidade comparticipativa e fiscalizadora, com vistas a impedir que, sob o argumento de otimização de valores sociais, neguem a participação dos envolvidos. É por meio do contraditório que se permite a problematização das alegações e argumentos jurídicos, reconstruindo, então, o caso concreto. Isso exige que o provimento, seja final ou interlocutório, considere as alegações e argumentos suscitados. Por fim, não se pode esquecer das demais garantias processuais, até porque há uma relação de codependências entre elas.

Ademais, é importantíssima a distinção entre os discursos-jurídicos de justificação e aplicação das normas, sendo que estes últimos pressupõem uma reconstrução exaustiva dos fatos relevantes para a solução da lide, por meio de uma interação argumentativa eminentemente técnica-jurídico, objetivando a dedução lógica-racional de qual norma, dentre as prima facie 
aplicáveis, é a adequada ao caso. Isso ocorre vez que uma questão não pode ser decidida, como aconteceu no I. P. $n^{\circ}$ 2.424-4 do STF, de forma abstrata (com argumentos de cunho axiológicos, relacionados com a validade das normas e, sobretudo, não suscitados pelas partes). Decisão esta, aliás, que se refere a uma Questão de Ordem, porque houve vários acórdãos atinentes, por exemplo, a Embargos de Declaração e Recebimento de Denúncia.

\section{REFERENCIAS}

ALEXY, Robert. Teorias dos direitos fundamentais. São Paulo: Malheiros Editores, 2008.

'La tesis del caso especial'. Isegoría, Madrid, n. 21, p. 23-35, 1999.

BARBOSA MOREIRA, José Carlos. A constituição e as provas ilicitamente obtidas. Revista Forense, Rio de Janeiro, v. 337, p. 125-134, 1995.

BARROS, Flaviane de Magalhães. (Re)forma do processo penal: comentários críticos dos artigos modificados pelas leis n. 11.690/08 e n. 11.719/08. Belo Horizonte: Del Rey, 2008.

BRASIL. Supremo Tribunal Federal. Decisão proferida nos autos do Inquérito Policial $\mathrm{n}^{\circ}$. 2.424-4. Relator: Ministro Cezar Peluso. Diário da Justiça, Brasília, 24 ago. 2007. Disponível em: < http://www.stf.jus.br/portal/processo/verProcessoAndamento.asp?incidente=2405920>. Acesso em: 20 jul. 2010.

CATTONI DE OLIVEIRA, Marcelo Andrade. Direito, política e filosofia: contribuição para uma teoria discursiva da constituição no marco do patriotismo constitucional. Rio de Janeiro: Lumem Júris, 2007.

. Jurisdição e hermenêutica constitucional no Estado democrático de Direito: um ensaio de teoria da interpretação enquanto teoria discursiva da argumentação jurídica de aplicação. In: (Org.). Jurisdição e hermenêutica constitucional no estado democrático de direito. Belo Horizonte: Mandamentos, 2004. v. 1, p. 47-78.

FAZZALARI, Elio. Instituições de direito processual. Campinas: Bookseller, 2006.

GALUPPO, Marcelo Campos. Princípios jurídicos e a solução de seus conflitos: a contribuição da obra de Alexy. Revista da Faculdade Mineira de Direito, Belo Horizonte, v. 1, n. 2, p. 134142, jul. 1998.

GOMES, Luiz Flávio; CERVINI SANCHEZ, Raúl. Interceptação telefônica: lei 9.296, de 24.07.96. São Paulo: Revista dos Tribunais, 1997.

GONÇALVES, Aroldo Plínio. Técnica processual e teoria do processo. Rio de Janeiro: Aide, 1992. 
GRECO FILHO, Vicente. Interceptação telefônica. São Paulo: Saraiva, 1996.

GRINOVER, Ada Pellegrini; FERNANDES, Antonio Scarance; GOMES FILHO, Antonio Magalhães. As nulidades no processo penal. 8. ed. rev. e atual. São Paulo: Revista dos Tribunais, 2006.

GÜNTHER, Klaus. The sense of appropriateness: application discourses in morality and law. New York: State University of New York Press, c1993.

. Un concepto normativo de coherencia para uma teoría de la

argumentación jurídica. Doxa: Cuaderno de Filosofia del Derecho, Alicante, n. 17-18, p. 271 302, 1995.

HABERMAS, Jürgen. Direito e democracia: entre facticidade e validade. Rio de Janeiro: Tempo Brasileiro, 1997. (Biblioteca Tempo Universitário, 101/102).

La constelácion posnacional: ensayos políticos. Barcelona: Paidós, 2000

LEAL, Rosemiro Pereira. Teoria geral do processo: primeiros estudos. 8. ed. rev. e atual. São Paulo: Forense, 2009.

NUNES, Dierle José Coelho. Processo jurisdicional democrático: uma análise crítica das reformas processuais. Curitiba: Juruá, 2008.

PEDRON, Flávio Quinaud. Comentários sobre as interpretações de Alexy e Dworkin. Revista CEJ, Brasília, n. 30, p. 70-80, jul./set. 2005.

TALAMINI, Eduardo. Prova emprestada no processo civil e penal. Revista de Informação Legislativa, Brasília, n. 140, p. 145-162, out./dez. 1998. 